\title{
The influence of exercise on the energy requirements of adult males in the UK
}

\author{
BY P. HAGGARTY ${ }^{1}$, G. MCNEILL ${ }^{1,2}$, M. K. ABU MANNEH ${ }^{1}$, L. DAVIDSON ${ }^{1}$, \\ E. MILNE' , G. DUNCAN' AND J. ASHTON ${ }^{1}$ \\ ${ }^{1}$ Rowett Research Institute, Bucksburn, Aberdeen AB2 9SB \\ ${ }^{2}$ Department of Medicine and Therapeutics, University of Aberdeen, $A B 92 Z D$
}

(Received 2 March 1993 - Revised 31 January 1994 - Accepted 10 May 1994)

\begin{abstract}
Energy expenditure was measured over $10 \mathrm{~d}$ using the doubly-labelled water (DLW) and activity diary methods in summer and winter in subjects with 'light' occupations but leisure activities which ranged from 'non-active' to 'very active'. The basal metabolic rate (BMR) and the energy cost of activities were determined by indirect calorimetry. The Department of Health (1991) predicted BMR for the group (6.89 (SD 0.30) $\mathrm{MJ} / \mathrm{d} ; \boldsymbol{n} 18$ ) was not significantly different from the measured value $(7 \cdot 17$ ( $(\mathrm{SD} 0.70) \mathrm{MJ} / \mathrm{d}$; $n$ 18). The range of DLW-derived expenditure values within the group was BMR $\times 1.41$ to 2.41 . The largest seasonal change within individuals was $B M R \times 0.5$. The energy expenditure of the group as a whole was lower in winter $(\mathrm{BMR} \times 1.88 ;$ SD 0.33; $n$ 9) than summer $(\mathrm{BMR} \times 2.01 ; \mathrm{SD} 0.30 ; n$ 9) though the difference was not statistically significant. The average summer and winter DLW-derived expenditure was BMR $\times 1.96$ (SD 0.31; $n$ 17). The activity diary estimate of expenditure was BMR $\times 1.79$ (SD $0.32 ; n$ 17). In a subset of the group who were representative of the most active $26 \%$ of all adult males in the UK, the DLW-derived expenditure was BMR $\times 2.08$ (SD 0.24; $n$ 11). This is higher than the highest Department of Health (1991) estimate of BMR $\times 1.6$ for individuals in light occupations. The measured energy costs of low-intensity activities were similar to those presented in the Department of Health (1991) report but the value determined for running $(B M R \times 13.08$; SD $2.4 ; n$ 6) was higher than the highest value in the report (BMR $\times 6$ to 8). The results indicate that the recent Department of Health (1991) reference values for energy may underestimate the expenditure of a significant proportion of the UK population largely because the energy costs of activity used in the report to calculate expenditure do not accurately reflect those achieved during active leisure in individuals who take regular exercise.
\end{abstract}

Energy expenditure: Exercise: Doubly-labelled water: Season

As opportunities for physical activity in the workplace are reduced by mechanization, leisure activity becomes increasingly important in determining overall activity levels (Allied Dunbar National Fitness Survey, 1992). One of the most popular reasons for participating in exercise during leisure time is to control or lose weight by increasing energy expenditure (Allied Dunbar National Fitness Survey, 1992). However, the recently published Department of Health (1991) reference values for the energy requirements of adults in the UK suggest that the potential of leisure activity to influence energy expenditure is extremely limited. For example, calculations based on the Department of Health (1991) report indicate that the difference in energy expenditure between the lowest and highest leisure activity categories for a typical $70 \mathrm{~kg}$ man with a light occupation would be $1.4 \mathrm{MJ} / \mathrm{d}$; this is less than the energy content of some popular chocolate bars. Furthermore, these new estimates are lower than previous values (Department of Health and Social Security, 1979) and their accuracy has yet to be fully tested. This can only be done by measuring the expenditure of individuals free to perform typical activities in their normal environment. 
However, the limitations of traditional field methodologies, e.g. measuring energy intake or determining the time spent in activities and energy cost of those activities, are well documented (see e.g. Durnin, 1984; Livingstone et al. 1990). The relatively recent application of the doubly-labelled water (DLW) method (Lifson \& McClintock, 1966) in combination with calorimetry to the estimation of free-living expenditure in man provides an objective alternative method.

The aim of the present study was to use the DLW method to determine the potential contribution of leisure activity to total energy expenditure in individuals with occupations classified as 'light' by the Department of Health (1991). The study was not designed as a survey, where subjects are selected to be representative of the population as a whole, because bias in the sample due to self-selection of health-conscious individuals can be difficult to avoid (Livingstone et al. 1991). This is particularly important when the sample size is small, as it is in most DLW studies due to the high cost of isotopically-labelled water. Instead, we set out to determine the likely range of possible expenditures in subjects with light occupations and used information on time allocation and the energy cost of activities to interpret the expenditure values in the context of the pattern of leisure activities found in the wider population.

Although the time of year has been considered to influence energy expenditure in populations involved in seasonal work such as farming in developing countries (McNeill et al. 1988 b) it has not been considered important in industrialized societies. However, leisure and sport activities are often seasonal, therefore if these do have an important influence on expenditure then energy expenditure in one season may not be representative of requirements over longer periods. In the present study energy expenditure was measured in the same subjects in both summer and winter in the UK.

\section{METHODS}

\section{Subjects}

Ten adult male volunteers were recruited for this study. The occupations of all subjects required them to sit for most of the working day and were classified as 'light' by the Department of Health (1991). However, leisure activities ranged from non-active to very active. Durnin (1985) has suggested that jogging or running is 'perhaps the commonest form of exercise' therefore the active subjects were chosen on the basis that this was their main active leisure time activity. During the DLW measurement period one of the subjects had to perform work activities which could not be classified as light and was therefore excluded from the study. On initial interview subjects 1 and 2 reported very little or no leisure activities whilst subjects 7,8 and 9 were selected because they were normally very active in their leisure time. The remainder of the subjects reported levels of leisure activity which were intermediate between these two extremes. All subjects were non-smokers and none was taking medication which might influence the outcome of the study. The age, occupation and physical characteristics of each subject are presented in Table 1 . The two most active subjects had body mass index (BMI) values of 20.0 whilst all but one of the less active individuals fell within the $20 \cdot 1-25 \cdot 0$ range. A recent survey (Allied Dunbar National Fitness Survey, 1992) indicates that $4 \%$ of adult males in the UK fall into the BMI range of 20.0 or less and that $47 \%$ are within the $20 \cdot 1-25 \cdot 0$ range. The DLW and activity diary study periods lasted $10 \mathrm{~d}$ and included one weekend. The measurements were carried out in summer (June-August) and winter (February-March) in Aberdeen.

The study was approved by the Joint Ethical Committee of Grampian Health Board and the University of Aberdeen. All subjects gave informed written consent to take part. 
Table 1. Subject details

\begin{tabular}{|c|c|c|c|c|c|}
\hline Subject no. & Occupation & Age (years) & Wt (kg) & Height (m) & BMI $\left(\mathrm{kg} / \mathrm{m}^{2}\right)$ \\
\hline 1 & Civil servant & 25 & 57.2 & 1.61 & $22 \cdot 1$ \\
\hline 2 & Civil servant & 40 & $71 \cdot 1$ & 1.82 & 21.5 \\
\hline 3 & Civil servant & 41 & $62 \cdot 4$ & 1.79 & $19 \cdot 5$ \\
\hline 4 & Lab technician & 36 & 76.8 & 1.81 & $23 \cdot 4$ \\
\hline 5 & Civil servant & 33 & 67.9 & 1.77 & $21 \cdot 7$ \\
\hline 6 & PhD student & 26 & $70 \cdot 6$ & 1.76 & $22 \cdot 8$ \\
\hline 7 & Lab technician & 43 & $70 \cdot 5$ & 1.73 & $23 \cdot 6$ \\
\hline 8 & Engineer & 42 & $59 \cdot 1$ & 1.72 & $20 \cdot 0$ \\
\hline 9 & Geo-chemist & 54 & 64.0 & 1.79 & 20.0 \\
\hline Mean & & 38 & 66.6 & 1.76 & 21.6 \\
\hline SD & & 9 & 6.39 & 0.06 & 1.52 \\
\hline
\end{tabular}

BMI, body mass index.

\section{Basal metabolic rate $(B M R)$}

BMR was measured under standard conditions in summer and winter. Subjects entered the residential unit at this Institute the evening before the BMR measurement and consumed a standard evening meal with an energy content one-third their estimated requirement, predicted from Department of Health (1991) equations on the basis of body-weight. Subjects had nothing further to eat or drink until the BMR measurement $12 \mathrm{~h}$ later at 07.00 hours. The BMR was measured by a ventilated-hood indirect calorimeter system (McNeill et al. 1988 a) in a room maintained at $24^{\circ}$ (summer and winter). The subject lay at rest under the hood for a period of $40 \mathrm{~min}$, of which the first $15 \mathrm{~min}$ and last $5 \mathrm{~min}$ were used to monitor room $\mathrm{O}_{2}$ and $\mathrm{CO}_{2}$ concentrations, with hood air monitored for the intervening $20 \mathrm{~min}$. Energy expenditure was calculated from the $\mathrm{O}_{2}$ consumption and $\mathrm{CO}_{2}$ production according to Weir (1949). Calibration of the system was carried out by combustion of weighed amounts of butane at regular intervals during the measurement period. After the BMR measurement, body weight was measured to the nearest $50 \mathrm{~g}$ and height was measured to the nearest $1 \mathrm{~mm}$.

\section{Activity diary/energy cost of activities}

During the summer and winter DLW measurement periods subjects were asked to record the time spent in various coded activities in 5 min blocks throughout the $10 \mathrm{~d}$ of the study. The predefined activities were: bed, dressing, lying, sitting, standing, light housework, heavy housework, walking at a moderate pace, and walking briskly or carrying a load. Additional codes were provided for up to three different kinds of sport activity and five miscellaneous activities to be defined by the subjects. The diary entries were checked every day to ensure accurate recording.

The energy cost of specific activities was determined during the summer measurement period. Standardized activities (e.g. sleeping, walking, sitting) were determined in a wholebody indirect calorimeter chamber during a $24 \mathrm{~h}$ run (McNeill et al. 1989). Sleeping metabolic rate was determined between midnight and 06.00 hours. The energy cost of additional work, sport and other leisure activities selected from the activity diaries was determined using an Oxylog portable $\mathrm{O}_{2}$ consumption meter (Humphrey \& Wolf, 1977). Subjects performed activities for $5 \mathrm{~min}$ before putting on the Oxylog with mouthpiece and nose clips and continued to carry out the activity for a further 5-10 min before the measurement was made for $10-15 \mathrm{~min}$. $\mathrm{O}_{2}$ consumed was used to calculate energy 
expenditure according to the formula: expenditure $(\mathrm{kJ})=20.92 \times \mathrm{O}_{2}$ consumption (litres) (Oxylog manual, P. K. Morgan, Gillingham, Kent). The Oxylog was calibrated as recommended in the manual and the calibration checked by simultaneous measurements of energy expenditure by the Oxylog and ventilated hood.

\section{Doubly-labelled water}

A venous blood sample of $20 \mathrm{ml}$ was taken immediately after the BMR measurement whilst subjects were still in the fasted state. Subjects then drank doubly-labelled water $(0 \cdot 19 \mathrm{~g}$ $\mathrm{H}_{2}{ }^{18} \mathrm{O}$ and $0.24 \mathrm{~g}^{2} \mathrm{H}_{2} \mathrm{O} / \mathrm{kg}$ body weight) and a second venous blood sample was taken $3 \mathrm{~h}$ later. A sample of urine was obtained from the second voiding of the day on each day of the study. All samples were analysed for ${ }^{18} \mathrm{O}$ to check that samples had not been mislabelled or contaminated and ${ }^{2} \mathrm{H}$ was measured on the first and last day of the study. The two-point method of calculation was used to estimate the rate constant and the pool size was determined by the increase in body water enrichment $3 \mathrm{~h}$ after dosing. The ratio of ${ }^{2} \mathrm{H}$ to ${ }^{18} \mathrm{O}$ pool sizes in summer was 1.042 (SD 0.018), in winter it was 1.033 (SD 0.006).

All isotope enrichments were determined on SIRA-10, SIRA-12 or SIRA Series II mass spectrometers (VG, Middlewich, Cheshire) relative to a series of laboratory reference waters previously calibrated against Vienna Standard Mean Ocean Water and Standard Light Antarctic Precipitation. The ${ }^{18} \mathrm{O}$ content of water was determined by equilibration with $\mathrm{CO}_{2}$ in vacutainers (Midwood et al. 1992) and ${ }^{2} \mathrm{H}$ by $\mathrm{Zn}$ reduction of water (Wong et al. 1987) with the modification that $500 \mathrm{mg} \mathrm{Zn}$ was used for each reduction. The mean standard error for mass spectrometer analysis was $0.4 \mathrm{ppm}$ for ${ }^{2} \mathrm{H}$ and $0.1 \mathrm{ppm}$ for ${ }^{18} \mathrm{O}$.

The exact method of calculation of fractionated water loss is still open to debate and the assumption of a single value for transcutaneous loss does not fully take account of the factors which are known to affect skin losses and may be too simplistic (Haggarty et al. $1988 b$ ). Fractionated water loss was calculated in the present study as the mid-point of a maximum physiological range and the uncertainty inherent in the range was incorporated into the estimate of precision of the final value for energy expenditure. Assuming that the breath is $95 \%$ saturated at $36^{\circ}\left(40 \mathrm{mg} \mathrm{H}_{2} \mathrm{O} / 1\right.$ breath) and that it contains $3.5 \% \mathrm{CO}_{2}$ (Schoeller \& Coward, 1990) the breath water loss can be calculated from the rate of $\mathrm{CO}_{2}$ production $\left(1 \cdot 14 \mathrm{~g} / 1 \mathrm{CO}_{2}\right)$. However, a problem occurs because a value for fractionated water loss is required to calculate the rate of $\mathrm{CO}_{2}$ production which is then used to calculate fractionated water loss. This can be overcome by an iterative approach where the uncorrected flux rates are used to calculate $\mathrm{CO}_{2}$ production initially; each parameter is then repeatedly calculated until it becomes stable and does not change with further iterations. Transcutaneous water loss is largely a function of skin temperature (Kuno, 1956). Kuno (1956) has estimated transcutaneous water loss to be $16 \mathrm{~g} / \mathrm{m}^{2}$ per $\mathrm{h}$ for a resting man at room temperature. This value doubles for a $10^{\circ}$ rise in skin temperature whilst, conversely, Schoeller et al. (1986) argue that it is halved because of the effect of clothing. The minimum fractionated water loss was estimated here using only breath water loss, and the maximum as the breath water loss plus the resting transcutaneous water loss measured by Kuno (1956). The value used in calculations was the mid-point and the range was incorporated into the overall precision on energy expenditure (Haggarty et al. 1994). This approach ensures that the DLW-derived expenditure values are accurate to within the given estimates of precision. The mean proportion of water loss which was fractionated (summer and winter) was estimated at 0.17 (SD 0.03).

Although we have advised caution when using the DLW method during growth (Haggarty, 1990) and weight loss (Haggarty et al. 1988a), we have not detected any significant bias resulting from physiological processes at weight stability (Haggarty et al. 1994). Therefore, since the subjects described here were all close to energy equilibrium we 
believe that there was no significant bias resulting from physiological processes; it is also worth bearing in mind that almost all known physiological processes (associated with both weight loss and weight gain) which affect the DLW method would result in an underestimate of expenditure (Haggarty et al. 1988 a; Haggarty, 1990) and in the present study the DLW-derived expenditure values were higher than those anticipated by the Department of Health (1991).

To convert DLW-derived $\mathrm{CO}_{2}$ production into expenditure it is necessary to know the respiratory quotient (RQ). Black et al. (1986) have suggested that a food quotient (FQ) of 0.85 is most appropriate for the average adult diet in the UK, with a between-subject coefficient of variation of $1.5 \%$. Alcohol intake can alter FQ but the level of alcohol consumption (self-recorded by the subjects in this study over the DLW measurement period) was low and would have a negligible effect on the assumed FQ of $0 \cdot 85$. Since there was no evidence for a change in body composition, even over 6 months, it was assumed that the mean RQ was equal to 0.85 over the DLW measurement period and the coefficient of variation reported by Black et al. (1986) was incorporated into the estimate of overall precision on energy expenditure (Haggarty et al. 1994).

\section{Statistics}

Significances of differences in weight, body fat, BMR and total energy expenditure between seasons were assessed by paired $t$ test; $P$ values of $<0.05$ were considered to be statistically significant.

\section{RESULTS}

The body weight of the group was almost identical in summer (66.56 (SD 6.36) $\mathrm{kg}$ ) and winter (66.57 (SD 5.96) kg; Table 2). Similarly, the mean fat-free mass (FFM) and the fat mass (calculated from the $\mathrm{H}_{2}{ }^{18} \mathrm{O}$ distribution space) were remarkably constant between seasons; the FFM in summer was 53.16 (SD 4.84) $\mathrm{kg}$ whilst in winter it was 53.23 (SD 4.28) $\mathrm{kg}$, the fat mass was 13.40 (SD 4.14) $\mathrm{kg}$ in summer and 13.34 (SD 4.72) $\mathrm{kg}$ in winter; as a percentage of body-weight the values were 19.96 (SD 5.20) and 19.80 (SD 5.75) \% respectively. There was no significant difference in any of these variables between summer and winter.

The BMR is largely determined by body weight and composition, therefore it was not surprising to find that the BMR was very similar between seasons; 7.19 (SD 0.59) $\mathrm{MJ} / \mathrm{d}$ in summer and 7.15 (SD 0.83) $\mathrm{MJ} / \mathrm{d}$ in winter $(t 0.31 ; P>0.05$; Table 3). In the Department of Health (1991) report, equations are provided to calculate the BMR from sex, age and weight and the values for total energy expenditure (TEE) are presented as multiples of the BMR. The Department of Health (1991) predicted BMR for the group (summer and winter) of 6.89 (SD 0.30 ) $\mathrm{MJ} / \mathrm{d}$, this was not significantly different $(t-1.9297 ; P>0.05$ ) from the measured BMR of $7 \cdot 17$ (SD 0.70) $\mathrm{MJ} / \mathrm{d}$.

The Department of Health (1991) report provides reference values for the energy expenditure of those individuals engaged in 'light' occupations as either BMR $\times 1.4,1.5$ or 1.6 depending on whether their leisure activity can be categorized as 'non-active', 'moderately active' or 'very active'. The TEE of the whole group in summer was BMR $\times 2.01$ (SD 0.30) and only one of the nine subjects fell below the highest Department of Health (1991) estimate of BMR $\times 1.6$. In winter three of the subjects had expenditures of $\mathrm{BMR} \times 1.6$ or below and the expenditure of the group as a whole was lower at BMR $\times 1.88$ (SD 0.33 ) though the difference was not statistically significant $(t-1.38$; $P>0.05$ ). Only one subject had an increase in expenditure in winter in excess of BMR $\times 0.1$ whilst in three of the subjects the drop in expenditure in winter was substantial 
Table 2. Body composition of male subjects in summer and winter

\begin{tabular}{|c|c|c|c|c|c|c|c|c|c|c|c|c|}
\hline \multirow[b]{2}{*}{$\begin{array}{c}\text { Subject } \\
\text { no. }\end{array}$} & \multicolumn{4}{|c|}{ Summer } & \multicolumn{4}{|c|}{ Winter } & \multicolumn{4}{|c|}{ Difference* } \\
\hline & $\begin{array}{c}\mathrm{Wt} \\
(\mathrm{kg})\end{array}$ & $\begin{array}{l}\text { FFM } \\
(\mathrm{kg}) \dagger\end{array}$ & $\underset{(\mathrm{kg})^{\dagger}}{\text { Fat }}$ & $\begin{array}{l}\text { Fat } \\
(\%)\end{array}$ & $\begin{array}{r}W t \\
(\mathrm{~kg})\end{array}$ & $\begin{array}{l}\text { FFM } \\
(\mathrm{kg}) \dagger\end{array}$ & $\underset{(\mathrm{kg}) \dagger}{\text { Fat }}$ & $\begin{array}{l}\text { Fat } \\
(\%)\end{array}$ & $\begin{array}{l}\text { Wt } \\
(\mathrm{kg})\end{array}$ & $\begin{array}{l}\text { FFM } \\
(\mathrm{kg})^{\dagger}\end{array}$ & $\begin{array}{c}\text { Fat } \\
(\mathrm{kg}) \dagger\end{array}$ & $\begin{array}{l}\text { Fat } \\
(\%)\end{array}$ \\
\hline 1 & $57 \cdot 20$ & $44-08$ & $13 \cdot 12$ & 22.94 & $58 \cdot 50$ & $44 \cdot 82$ & 13.68 & $23 \cdot 39$ & $+1 \cdot 30$ & +0.74 & +0.56 & +0.45 \\
\hline 2 & $71 \cdot 10$ & $50 \cdot 28$ & $20 \cdot 82$ & $29 \cdot 29$ & $74 \cdot 10$ & $50 \cdot 36$ & 23.74 & 32.03 & +3.00 & +0.08 & +2.92 & +2.74 \\
\hline 3 & $62 \cdot 40$ & $51 \cdot 37$ & 11.03 & 17.68 & $62 \cdot 50$ & $53 \cdot 29$ & $9 \cdot 21$ & $14 \cdot 73$ & $+0 \cdot 10$ & +1.92 & -1.82 & -2.95 \\
\hline 4 & $76 \cdot 80$ & $60 \cdot 06$ & $16 \cdot 74$ & 21.80 & $74 \cdot 25$ & 58.47 & $15 \cdot 78$ & $21 \cdot 26$ & -2.55 & -1.59 & -0.96 & -0.54 \\
\hline 5 & 67.90 & 53.81 & 14.09 & $20 \cdot 76$ & 67.85 & 53.01 & 14.84 & 21.87 & -0.05 & $-0 \cdot 80$ & +0.75 & $+1 \cdot 11$ \\
\hline 6 & $70 \cdot 10$ & $55 \cdot 85$ & $14 \cdot 26$ & $20 \cdot 34$ & $69 \cdot 30$ & $56 \cdot 60$ & $12 \cdot 70$ & $18 \cdot 33$ & -0.80 & $+0 \cdot 75$ & $-1 \cdot 56$ & $-2 \cdot 01$ \\
\hline 7 & $70 \cdot 50$ & $55 \cdot 92$ & $14 \cdot 58$ & 20.76 & 69.75 & 56.92 & 12.83 & 18.39 & -0.75 & +1.00 & $-1 \cdot 75$ & $-2 \cdot 28$ \\
\hline 8 & $59 \cdot 05$ & $49 \cdot 65$ & $9 \cdot 40$ & 15.92 & $58 \cdot 70$ & 50.06 & $8 \cdot 65$ & $14 \cdot 73$ & -0.35 & +0.41 & -0.75 & $-1 \cdot 19$ \\
\hline 9 & 64.00 & $57 \cdot 45$ & 6.55 & $10 \cdot 24$ & $64 \cdot 20$ & $55 \cdot 55$ & 8.65 & 13.48 & +0.20 & -1.90 & $+2 \cdot 10$ & $+3 \cdot 24$ \\
\hline Mean & 66.56 & $53 \cdot 16$ & $13 \cdot 40$ & 19.96 & $66 \cdot 57$ & $53 \cdot 23$ & $13 \cdot 34$ & $19 \cdot 80$ & +0.01 & -0.07 & 0.06 & -0.17 \\
\hline SD & $6 \cdot 36$ & $4 \cdot 84$ & $4 \cdot 14$ & $5 \cdot 20$ & $5 \cdot 96$ & $4 \cdot 28$ & $4 \cdot 72$ & $5 \cdot 75$ & 1.52 & 1.26 & 1.73 & $2 \cdot 22$ \\
\hline
\end{tabular}

FFM, fat-free mass.

* Summer and winter means were not significantly different.

+ FFM and body fat were calculated assuming that : body water $=\mathrm{H}_{2}{ }^{18} \mathrm{O}$ space $/ 1 \cdot 01, \mathrm{FFM}=0 \cdot 732 \times$ body water, and body fat = body weight - FFM.

Table 3. Energy expenditure by male subjects in summer and winter*

\begin{tabular}{|c|c|c|c|c|c|c|c|c|c|c|c|}
\hline \multirow[b]{3}{*}{$\begin{array}{c}\text { Subject } \\
\text { no. }\end{array}$} & \multicolumn{4}{|c|}{ Summer } & \multicolumn{4}{|c|}{ Winter } & \multicolumn{3}{|c|}{ Difference $\nmid$} \\
\hline & \multirow[b]{2}{*}{$\begin{array}{l}\text { BMR } \\
(\mathrm{MJ} / \mathrm{d})\end{array}$} & \multicolumn{2}{|c|}{$\operatorname{TEE}(\mathrm{MJ} / \mathrm{d})$} & \multirow[b]{2}{*}{$\begin{array}{c}\text { TEE } \\
(\times \mathrm{BMR})\end{array}$} & \multirow[b]{2}{*}{$\begin{array}{l}\text { BMR } \\
(\mathrm{MJ} / \mathrm{d})\end{array}$} & \multicolumn{2}{|c|}{ TEE $(\mathrm{MJ} / \mathrm{d})$} & \multirow[b]{2}{*}{$\begin{array}{c}\text { TEE } \\
(\times \mathrm{BMR})\end{array}$} & \multirow[b]{2}{*}{$\begin{array}{l}\text { BMR } \\
(\mathrm{MJ} / \mathrm{d})\end{array}$} & \multirow[b]{2}{*}{$\begin{array}{c}\text { TEE } \\
(\mathrm{MJ} / \mathrm{d})\end{array}$} & \multirow[b]{2}{*}{$\begin{array}{c}\text { TEE } \\
(\times \text { BMR })\end{array}$} \\
\hline & & Mean & $\mathbf{S E}$ & & & Mean & $\mathrm{SE}$ & & & & \\
\hline 1 & 6.65 & $10 \cdot 00$ & 0.26 & 1.50 & $6 \cdot 12$ & 9.88 & 0.26 & 1.62 & +0.54 & $-0 \cdot 12$ & +0.11 \\
\hline 2 & $7 \cdot 14$ & $12 \cdot 49$ & $0 \cdot 31$ & 1.75 & 6.68 & $10 \cdot 33$ & 0.36 & 1.55 & $-0 \cdot 46$ & $-2 \cdot 17$ & -0.20 \\
\hline 3 & 6.99 & 12.50 & $0 \cdot 38$ & 1.79 & $7 \cdot 16$ & 10.09 & 0.47 & 1.41 & +0.17 & $-2 \cdot 41$ & $-0 \cdot 38$ \\
\hline 4 & $7 \cdot 49$ & 14.64 & 0.44 & 1.95 & 7.36 & 14.90 & 0.34 & 2.03 & -0.13 & $+0 \cdot 26$ & +0.07 \\
\hline 5 & 7.04 & 15.92 & 0.40 & $2 \cdot 26$ & 6.81 & 11.91 & 0.38 & 1.75 & -0.23 & -4.01 & $-0-51$ \\
\hline 6 & 7.64 & 15.61 & 0.35 & 2.04 & 7.65 & $17 \cdot 19$ & 0.33 & $2 \cdot 25$ & +0.01 & $+1 \cdot 58$ & +0.20 \\
\hline 7 & 7.53 & $15 \cdot 19$ & 0.34 & $2 \cdot 02$ & $8 \cdot 30$ & 17.23 & 0.47 & 2.08 & -0.77 & $+2 \cdot 04$ & +0.06 \\
\hline 8 & 613 & 14.46 & 0.21 & $2 \cdot 36$ & 6.03 & 14.23 & 0.59 & $2 \cdot 36$ & $-0 \cdot 10$ & -0.23 & 0 \\
\hline 9 & 8.12 & $19 \cdot 59$ & 0.43 & $2 \cdot 41$ & 8.26 & 15.84 & 0.47 & 1.92 & +0.14 & $-3 \cdot 76$ & $-0 \cdot 50$ \\
\hline Mean & $7 \cdot 19$ & $14 \cdot 49$ & 0.35 & $2 \cdot 01$ & $7 \cdot 15$ & $13 \cdot 51$ & 0.41 & 1.88 & -0.08 & -0.98 & $-0-13$ \\
\hline SD & 0.59 & $2 \cdot 69$ & 0.08 & $0 \cdot 30$ & 0.83 & 3.01 & $0 \cdot 10$ & 0.33 & 0.38 & $2 \cdot 20$ & 0.28 \\
\hline
\end{tabular}

BMR, basal metabolic rate; TEE, total energy expenditure.

* For details of measurement techniques, see pp. 801-803.

$\dagger$ Summer and winter means were not significantly different.

$($ BMR $\times 0.4-0.5)$. When shorter day length and adverse weather conditions in winter are taken into account then it is perhaps not surprising to find a large fall in expenditure in winter in individuals for whom the largest contribution to expenditure comes from outdoor leisure activities, and indeed two of the three subjects with the highest TEE exhibited the biggest drop in expenditure in winter $(\geqslant B M R \times 0.5)$.

Estimates of energy requirements should reflect habitual levels of expenditure over extended periods and the potential for seasonal variation in expenditure is well illustrated in this group. However, even when this is taken into account and an average summer and 
winter TEE calculated for each individual only two of the subjects had expenditure values $(B M R \times 1.56$ and 1.60) which fell within the highest Department of Health (1991) estimate for individuals with 'light' occupations (BMR $\times 1 \cdot 4-1 \cdot 6)$.

Table 4 summarizes the total 'active leisure' time (used by the Department of Health, 1991) of each subject in each season together with the overall 'activity level' category (using the Allied Dunbar National Fitness Survey (1992) classification) calculated from the activity diaries. It can be seen that, of the seventeen DLW-derived energy expenditure and activity level estimates (one subject did not complete the winter activity diary), $29 \%$ of the observations fell into category $5,35 \%$ in category $4,6 \%$ in category $3,12 \%$ in category $2,6 \%$ in category 1 and $12 \%$ in category 0 . Thus the values cover the full range of activity levels with the majority of measurements in the two most active categories.

In the Department of Health (1991) report it is assumed that $2 \mathrm{~h}$ of the $10.5 \mathrm{~h} / \mathrm{d}$ of leisure time is spent in 'active leisure'. Despite the fact that TEE was substantially higher than Department of Health (1991) estimates in most of the subjects described here the mean time spent in 'active leisure' was only $1.5 \mathrm{~h}$ (range $0 \cdot 1-3 \cdot 8$ ). The discrepancy between estimated and measured expenditure must therefore be due to a difference in the energy costs of the activities performed during active leisure.

Table 5 shows measured energy costs of the most important leisure activities. Most values agreed reasonably well with those given in the Department of Health (1991) report (where an equivalent activity could be found) and in some cases the estimates were slightly higher than the measured values (see e.g. gardening or yoga). However, a comparison of the higher intensity activities undertaken during active leisure was not possible as there was no category higher than average jogging at BMR $\times 6$ to 8 in the Department of Health (1991) report. In the subjects described in the present study the measured BMR multiples during running ranged from $B M R \times 10.73$ to 17.00 (mean, BMR $\times 13.08$ ). Because the energy cost of running in subject $8(B M R \times 17)$ was so much higher than anticipated by the Department of Health (1991) report, the Oxylog measurement of the energy cost of running was repeated some months after completion of the study and the second estimate of BMR $\times 16$ confirmed the validity of the original measurement. However, continuous monitoring of heart rate during the $10 \mathrm{~d}$ summer DLW and activity diary period (Davidson et al. 1993) indicated that the mean heart rate of this subject during running was 20 beats/min below that recorded when measuring the energy cost of this activity, indicating that the measured energy cost was accurate but higher than that normally achieved during habitual performance of the activity. Similar heart rate comparisons in the other subjects indicated a smaller effect but that the energy expended during the Oxylog measurement was generally lower than the habitual level of expenditure. This variability in the response of subjects to measurement is a well recognized problem with the activity diary method (Durnin, 1984) but the additional heart rate information leads us to the conclusion that the mean energy cost of running in this group of BMR $\times 13$ was a good estimate of the mean habitual level of expenditure.

The energy cost of an activity such as running is not fixed but varies between individuals and even within an individual at different fitness levels (Durnin, 1985). It has been estimated that the maximal aerobic capacity of a highly trained athlete would be about BMR $\times 20$ whilst in an untrained man a value of BMR $\times 12$ would be more usual (Durnin, 1985). Training not only increases the maximal aerobic capacity but also the percentage of maximal $\mathrm{O}_{2}$ uptake which can be sustained during exercise and activities such as jogging or running would typically be performed at $50-70 \%$ of maximal $\mathrm{O}_{2}$ uptake. The frequency with which an individual participates in exercise will determine where they fall within this range. Furthermore, after completion of exercise performed at or above $50 \%$ of maximal aerobic capacity, the metabolic rate can remain elevated for as much as $12 \mathrm{~h}$ after exercise 
Table 4. Overall time spent in active leisure by male subjects ranked in order of doublylabelled water $(D L W)$-derived energy expenditure (expressed as a multiple of basal metabolic rate $(B M R))$

\begin{tabular}{|c|c|c|c|c|}
\hline $\begin{array}{c}\text { Subject } \\
\text { no. }\end{array}$ & Season & $\begin{array}{l}\text { Total active leisure* } \\
(\mathrm{min} / \mathrm{d})\end{array}$ & $\begin{array}{l}\text { Activity level } \\
\text { category } \dagger\end{array}$ & $\begin{array}{c}\text { DLW-derived } \\
\text { expenditure }(\times \text { BMR })\end{array}$ \\
\hline 3 & W & 16 & 2 & 1.41 \\
\hline 1 & $\mathbf{S}$ & 29 & 1 & $1 \cdot 50$ \\
\hline 2 & W & 0 & 0 & 1.55 \\
\hline 1 & W & 55 & 4 & 1.62 \\
\hline 2 & $\mathrm{~S}$ & 4 & 0 & 1.75 \\
\hline 3 & $S$ & 104 & 4 & $1 \cdot 79$ \\
\hline 9 & W & 134 & 5 & 1.92 \\
\hline 4 & $\mathrm{~S}$ & 64 & 4 & 1.95 \\
\hline 7 & $\mathrm{~S}$ & 121 & 4 & $2 \cdot 02$ \\
\hline 4 & $\mathbf{W}$ & 35 & 2 & $2 \cdot 03$ \\
\hline 6 & $\mathrm{~S}$ & 115 & 3 & $2 \cdot 04$ \\
\hline 7 & W & 135 & 5 & $2 \cdot 08$ \\
\hline 6 & W & 48 & 4 & $2 \cdot 25$ \\
\hline 5 & $\mathrm{~S}$ & 49 & 4 & $2 \cdot 26$ \\
\hline 8 & $\mathrm{~S}$ & 229 & 5 & $2 \cdot 36$ \\
\hline 8 & W & 181 & 5 & $2 \cdot 36$ \\
\hline 9 & $\mathrm{~S}$ & 95 & 5 & $2 \cdot 41$ \\
\hline
\end{tabular}

$\mathrm{S}$, summer; W, winter.

* Calculated as the time spent in sport, heavy housework, brisk walking, load carrying and other miscellaneous leisure activities.

$\dagger$ According to activity classification presented in the Allied Dunbar National Fitness Survey (1992).

Table 5. Energy cost of activities expressed as multiples of the measured basal metabolic rate*

\begin{tabular}{|c|c|c|c|c|}
\hline \multirow[b]{2}{*}{ Activity } & \multicolumn{3}{|c|}{ Measured } & \multirow{2}{*}{$\begin{array}{l}\text { Department of } \\
\text { Health (1991) range }\end{array}$} \\
\hline & Mean & Range & $n$ & \\
\hline Bed & 1.01 & $0 \cdot 90-1 \cdot 17$ & 9 & $1 \cdot 0$ \\
\hline Sitting & 1.56 & $1 \cdot 39-1 \cdot 76$ & 9 & $1 \cdot 0-1 \cdot 4$ \\
\hline Standing & 1.83 & $1 \cdot 45-2 \cdot 46$ & 9 & $1 \cdot 5-1 \cdot 8$ \\
\hline $\begin{array}{l}\text { Walking at moderate pace } \\
\text { or light housework }\end{array}$ & $2 \cdot 54$ & $2 \cdot 27-3 \cdot 29$ & 9 & $2 \cdot 5-3 \cdot 3$ \\
\hline $\begin{array}{l}\text { Walking briskly or carrying } \\
\text { a load }\end{array}$ & 4.09 & $3 \cdot 65-4 \cdot 90$ & 9 & $3 \cdot 4-4 \cdot 4$ \\
\hline Laboratory work & 1.95 & $1.88-1.99$ & 4 & $1 \cdot 5-1 \cdot 8$ \\
\hline Jogging or running & 13.08 & $10.73-17.00$ & 6 & $6 \cdot 0-7 \cdot 9$ \\
\hline Gardening & 2.88 & & 1 & $3 \cdot 4-4 \cdot 4$ \\
\hline Car repair & 3.81 & & 1 & $3 \cdot 4-4 \cdot 4$ \\
\hline Decorating & $1 \cdot 75$ & & 1 & $2 \cdot 5-3 \cdot 3$ \\
\hline Yoga & 3.06 & & 1 & $4 \cdot 5-5 \cdot 9$ \\
\hline
\end{tabular}

* For details of procedures, see pp. 801-803.

(Maehlum et al. 1986) and the magnitude of the effect varies linearly with the duration and exponentially with the intensity of the exercise (Bahr, 1992). Bahr (1992) estimated that moderate exercise (intensity about $50 \%$ of maximal aerobic capacity for more than $1 \mathrm{~h}$ ) would result in a post-exercise expenditure of $50-100 \mathrm{~kJ}$ whereas vigorous exercise 


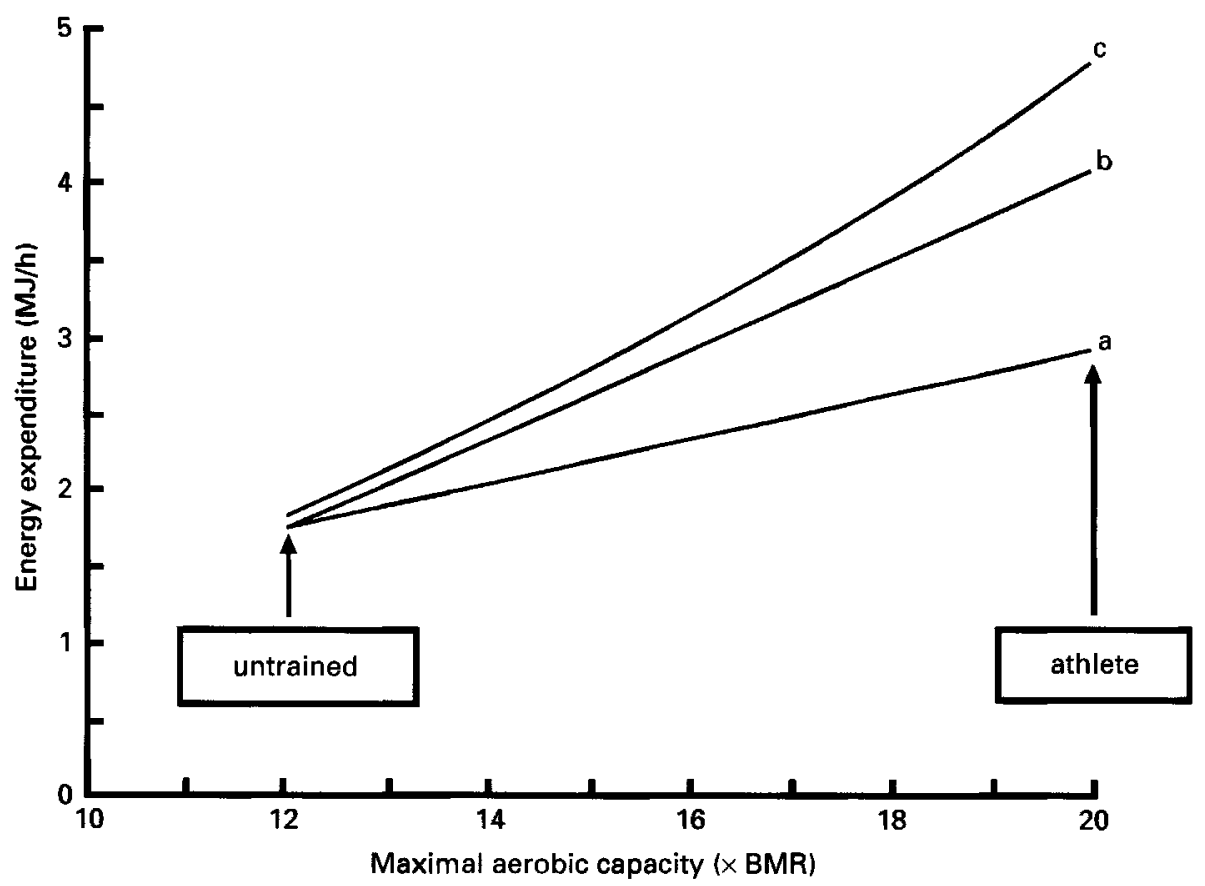

Fig. 1. The effect of training on the energy expenditure during $1 \mathrm{~h}$ running in a $70 \mathrm{~kg}$ male (basal metabolic rate (BMR) $7 \mathrm{MJ} / \mathrm{d}$ ); (a) assuming that expenditure is always $50 \%$ of maximal aerobic capacity, (b) assuming that the proportion of maximal aerobic capacity achieved increases linearly from 50 to $70 \%$ with increasing fitness, and (c) assuming that post-exercise oxygen consumption is $75 \mathrm{~kJ}$ for $1 \mathrm{~h}$ exercise at $50 \%$ maximal aerobic capacity and $700 \mathrm{~kJ}$ at $70 \%$ (Bahr, 1992).

(intensities of $70 \%$ or more) would result in an excess post-exercise expenditure of $700 \mathrm{~kJ}$. The effect of these processes is additive and the impact on the energy cost of exercise in a $70 \mathrm{~kg}$ man is illustrated in Fig. 1. It can be seen from this Figure that the energy cost of running can vary by a factor of 2.7 (or by $3 \mathrm{MJ}$ for $1 \mathrm{~h}$ of exercise) depending on the level of fitness of the individual. In terms of BMR multiples this range corresponds to BMR $\times 6$ to $B M R \times 16$. Thus the energetic cost of $1 \mathrm{~h}$ of exercise is not only variable but increases more than linearly with the increase in maximal aerobic capacity brought about by regular exercise. Although the full physiological range (from untrained individual to athlete) is presented in Fig. 1 it can be seen that this effect will apply at all levels of fitness. The wide variability in the energy cost of exercise predicted by such calculations is supported by the data from the present study.

The Department of Health (1991) estimates of expenditure are based on three possible occupation and leisure categories but it is recommended that, where possible, more detailed information on time allocation should be obtained. Using the time-allocation data from the activity diary, and measured energy costs of activity where no literature values were available or appropriate, an estimate of TEE was derived using the approach suggested in the report. The mean TEE for the seventeen observations calculated this way would have been BMR $\times 1.79$ (SD 0.32) compared with the DLW-derived value of BMR $\times 1.96($ SD 0.31). When the activity diary TEE is plotted against the DLW-derived TEE as in Fig. 2 it can be seen that the activity diary underestimated TEE in eleven of the seventeen determinations and the tendency was for the discrepancy to increase with increasing expenditure with the exception of subject 8 whose summer and winter diary-derived TEE estimates both 


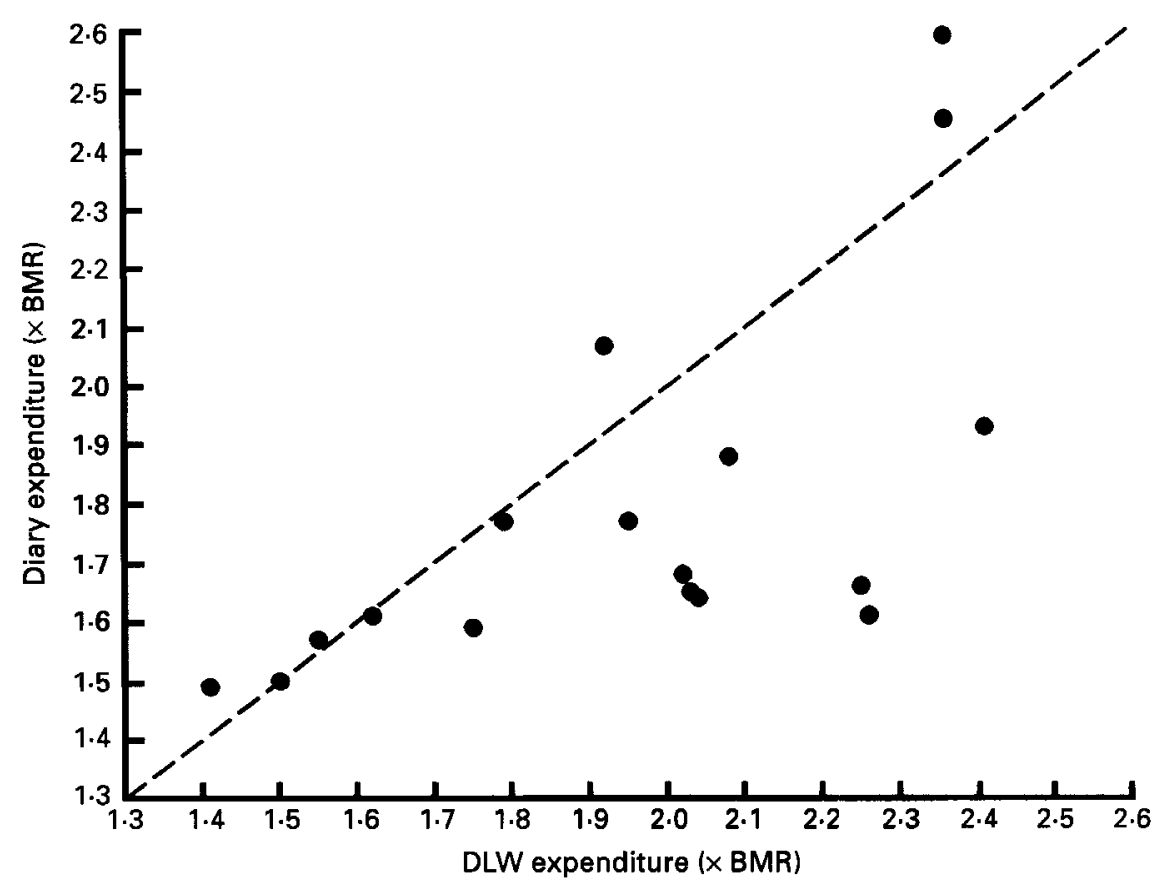

Fig. 2. Comparison of activity diary-derived energy expenditure (using the measured energy costs of activities) with that determined using doubly-labelled water (DLW), expressed as a multiple of the basal metabolic rate (BMR).

appeared to overestimate the true TEE. This may partly be explained by the fact that, as discussed above, the measured energy cost of running overestimated the habitual level of expenditure during running in this subject.

\section{DISCUSSION}

The majority of adults in the UK fall below an acceptable activity level threshold that would confer significant health and functional benefits and there is general agreement that an increase in activity level is to be encouraged (Allied Dunbar National Fitness Survey, 1992). When questioned on the factors which motivate them to take exercise, $60 \%$ of males and $72 \%$ of females said that control or loss of weight was very important and a number of the other reasons given were also related to the energetic consequences of exercise (Allied Dunbar National Fitness Survey, 1992). However, by choosing energy reference values of BMR $\times 1.4,1.5$ and 1.6 for those in 'light' occupations, the Department of Health (1991) report implies that the TEE of this group lies very close to the minimum compatible with normal sedentary life (BMR $\times 1.35$; Livingstone et al. 1990) and that even large changes in leisure activity will have only small effects on TEE. In contrast, our results suggest that leisure activity can have a significant impact on TEE. The lowest value of BMR $\times 1.41$, determined in an inactive subject in winter, is very close to the minimum TEE compatible with normal life whilst the highest single value of $\mathrm{BMR} \times 2 \cdot 41$, obtained in an extremely active subject in summer, is probably very close to an upper limit on the TEE of individuals with full-time sedentary occupations.

It is stated in the Department of Health (1991) report that better estimates of expenditure may be obtained from more detailed information on time use and measured energy costs 
of activities. However, as predicted by Durnin (1984), we found this approach to yield extremely variable results, even when using a comprehensive activity diary and individual measurement of the energy costs of specific activities. This is perhaps not surprising given the potential errors in time allocation by subjects, the difficulty of ascribing all activities to a small number of representative categories, measuring the energy cost of those selected activities, and the assumption that the transition from one level of expenditure to another is instantaneous. These problems are exacerbated in subjects where the TEE is heavily influenced by short-duration, high-expenditure activities, as in individuals with 'light' occupations but 'very active' leisure, since a small error in the measured or estimated cost of the high-expenditure activity will result in a large error in TEE.

More important than the degree of variability in the activity diary-derived TEE was the indication that the time-allocation approach underestimated TEE in many of the more active subjects. High-intensity activities are generally the most difficult to measure using traditional methods since the process of measurement may itself affect the level of expenditure. This phenomenon may partly be explained by the cumbersome nature of the portable $\mathrm{O}_{2}$ analyser and the discomfort caused by wearing the mouthpiece and nose clip, particularly when used during vigorous physical exertion, as when running. Most of the subjects in the present study complained of discomfort during the measurement and, although exhorted to perform each measured activity as normal, it is possible that, in some individuals, the measured expenditure fell short of that achieved without the Oxylog; e.g. in subject 9 (highest TEE), where the activity diary method significantly underestimated expenditure, the running heart rate was lower during the Oxylog measurement than when unencumbered by the Oxylog. Furthermore, an inherent assumption in the activity diary method is that the transition from one level of expenditure to another is instantaneous. This is a reasonable assumption in subjects whose level of expenditure varies little during the day but it may not be valid in individuals where excess post-exercise $\mathrm{O}_{2}$ consumption (EPOC) during the transition from a high level of expenditure to a low one may be substantial. This error will be compensated to some extent due to the lag in the time taken to achieve the maximum level of expenditure for any given activity but the magnitude of this phenomenon is likely to be small in relation to EPOC. If ignored, the effect of EPOC will be to cause the activity diary method to underestimate TEE, with the magnitude being greatest in the most active individuals. This is consistent with the results presented here.

Although detailed time allocation is the approach recommended by the Department of Health (1991), the report is most likely to be used by those who cannot perform such additional measurements and who must make do with the values provided. It is therefore important that these values should be reasonably representative of the population but there is no indication in the report as to whether most of the UK population is expected to fall into one of the three categories (and if so in what ratios), or, for example, whether the three expenditure estimates are based on activity levels that the majority of people would associate with the subjective descriptions of 'non-active', 'moderately-active' or 'very active'.

An indication of how representative the DLW-derived TEE values presented here are may be obtained by relating the activity patterns of these subjects to those found in the population as a whole. In the first comprehensive survey of activity patterns in the UK (Allied Dunbar National Fitness Survey, 1992), individuals were allocated to one of six activity level categories depending on the intensity and frequency of activities. Of the adult males surveyed, $14 \%$ were engaged in three or more sessions of vigorous activity per week (category 5), 12\% in three or more sessions of moderate to vigorous activity per week (category 4), 23\% in three or more sessions of moderate activity per week (category 3 ), $18 \%$ in two to three sessions of mixed moderate and vigorous activity per week (category 
2), $16 \%$ in one occasion of mixed moderate and vigorous activity (category 1 ) and $17 \%$ taking no exercise (category 0 ). The report also noted that a slightly higher proportion of those in the professional and intermediate non-manual groups engaged in vigorous activity, thereby increasing the percentages in the higher activity categories for those in 'light' occupations. The average duration of these sessions ranged from $1 \mathrm{~h}$ for vigorous activities to $2 \mathrm{~h}$ for light activities, therefore, making the conservative assumption that all sessions lasted for $1 \mathrm{~h}$, we may conclude that about a quarter of adult males in the UK take part in $25 \mathrm{~min} / \mathrm{d}$ vigorous or moderate to vigorous activity (categories 4 and 5). The TEE values obtained in the present study for subjects allocated to these categories were very variable but we can safely conclude that they were substantially higher (BMR $\times 2 \cdot 23$ (SD $0 \cdot 21 ; n 5)$ for category 5 and 1.95 (SD $0 \cdot 25 ; n$ 6) for category 4 ) than the highest Department of Health (1991) estimate for those in 'light' occupations (BMR $\times 1 \cdot 6)$. This conclusion is borne out by other DLW-derived TEE values for adult males in developed countries (Livingstone $e t$ al. 1991; Roberts et al. 1991; Westerterp et al. 1992).

There is only one other report of DLW-derived TEE values in adult males in the UK (Livingstone et al. 1991) and for the eight subjects in the study who could be considered to be employed in 'light' occupations the average TEE was BMR $\times 1.83$ (range 1.44-2.24); only two individuals had TEE values below BMR $\times 1 \cdot 6$. Roberts et al. (1991) obtained values of BMR $\times 1.98$ (range 1.57-2.60) in young males in the USA and Westerterp et al. (1992) measured a TEE of BMR $\times 1.63$ (range 1.4-2.1) in adult Dutch males "who did not participate in any sport like running or jogging and who were not active in any other sport for more than $1 \mathrm{~h} /$ week', although no information on occupation is given. More direct evidence that regular exercise can have a significant effect on total energy expenditure comes from the study of Westerterp et al. (1992) who showed that an imposed exercise programme (average duration $35 \mathrm{~min} / \mathrm{d}$ ), undertaken by untrained adult males, increased the daily energy expenditure by BMR $\times 0.5$. Taken together with the results of the present study it can be seen that the TEE of adult males is higher than present Department of Health (1991) estimates and extremely variable between individuals within a superficially homogeneous group.

There has, however, been some difficulty in explaining these results on the basis of the energy costs of activity presented in the Department of Health (1991) report and crude estimates of the activity levels of the subjects studied. Livingstone et al. (1991) suggested that the high expenditures they observed could be accounted for by $2 \mathrm{~h} / \mathrm{d}$ of activities such as brisk walking, tennis, cycling and gardening yet the actual time spent in active leisure by the subjects in this study (estimated by interview questionnaire) was only $1 \cdot 2 \mathrm{~h} / \mathrm{d}$. Roberts et al. (1991) suggested that, since they could not account for the expenditure values on the basis of estimated activity levels, the heat increment of feeding or even fidgeting should be considered. It is, however, extremely unlikely that these factors could explain the energy expenditures observed. The most likely explanation for the emerging discrepancy between the Department of Health (1991) estimates of the energetic consequences of leisure activity and those measured directly is a failure to take account of the way in which leisure activity is currently performed since, on the basis of the energy costs of activities given in the report, individuals would have to spend improbable amounts of time in active leisure pursuits to increase expenditure much above the suggested BMR multiples.

To explain this discrepancy we must look to the original source of the values for the energy costs of activity used in the report to evaluate their relevance to contemporary lifestyles. Unfortunately, no references are given by the Department of Health (1991) for the individual energy costs but two other publications which list BMR multiples for various activities, and give similar or lower values for the energy cost of jogging or running, are the Food and Agriculture Organization/World Health Organization/United Nations Uni- 
versity (FAO/WHO/UNU, 1985) report Protein and Energy Requirements and James \& Schofield's (1990) book Human Energy Requirements. In the latter the relevant references for the energy costs presented are 'Schofield, Dallosso and James, unpublished data' and FAO/WHO/UNU (1985); the latter is also referred to in the Department of Health (1991) report. As with the Department of Health (1991) report, the primary sources of the energy costs used by FAO/WHO/UNU are not cited individually, but the most appropriate general reference seems to be Energy, Work and Leisure by Passmore \& Durnin (1967). However, these authors did not measure the energy cost of running but, instead, cite the classic paper of Margaria et al. (1963) entitled Energy Cost of Running and measurements by Edholm et al. (1955) on ten young men. Thus, the studies of Margaria et al. (1963) and Edholm et al. (1955) appear to provide the primary data for the energy cost of jogging or running.

The average expenditure of the ten subjects studied by Edholm et al. (1955) would be equivalent to $3 \mathrm{MJ} / \mathrm{h}$ (or BMR $\times 10.3$ for a $70 \mathrm{~kg}$ male) and this is the value recommended by Passmore \& Durnin (1967) 'in the absence of measurements'. In a more rigorous study, Margaria et al. (1963) measured the energy expenditure of trained athletes and untrained individuals over a wide range of speeds and concluded that the energy cost of running on level ground depended only on body weight and the distance covered; the actual speed of running had little effect on the energy cost per $\mathrm{km}$. These authors did, however, find an effect of training which was actually to reduce energy expenditure by 5-7\% for any given distance covered because of the increased efficiency that comes with improved technique. Margaria et al. (1963) estimated values for the energy cost of running to be $4.2 \mathrm{~kJ} / \mathrm{kg}$ per $\mathrm{km}$ in athletes and $4.4 \mathrm{~kJ} / \mathrm{kg}$ per $\mathrm{km}$ in untrained individuals. Using these values we can calculate that a $70 \mathrm{~kg}$ athlete, running at a very modest $10 \mathrm{~km} / \mathrm{h}(6 \mathrm{miles} / \mathrm{h}$ or $10 \mathrm{~min}$ miles; categorized as moderately fast jogging by Durnin, 1985), would expend $2.9 \mathrm{MJ} / \mathrm{h}$ $(B M R \times 10.0)$ whilst an untrained individual of the same body weight, running at the same speed, would expend 3.1 MJ/h $(B M R \times 10 \cdot 6)$; at the top of the range, an athlete running at $20 \mathrm{~km} / \mathrm{h}$ would expend $6 \mathrm{MJ} / \mathrm{h}(\mathrm{BMR} \times 20)$. It should be noted that these estimates, determined on level ground with no wind resistance, will be augmented under normal conditions. For example, the extra energy expended in running uphill is greater than that saved when running back down the same hill; Margaria et al. (1963) have estimated that the energy expended per $\mathrm{km}$ is increased by $3 \%$ if the exercise time is equally divided between running up and down a $5 \%$ gradient, the increase is $10 \%$ for a $10 \%$ gradient. However, even without such considerations, we can safely conclude that the energy expended during jogging or running can vary over a very wide range and that the values on which the Department of Health (1991) and FAO/WHO/UNU (1985) reports appear to be based are consistent with the measured energy costs of running reported here (mean, $\mathrm{BMR} \times 13$, range, $\mathrm{BMR} \times 10$ to 17 ) and theoretical calculations of the effect of training, yet the energy costs used in the above reports are significantly lower.

Part of the reason for this discrepancy may be that some of the energy costs presented in the reports have apparently been corrected to take account of 'rest periods' and 'normal variants' in the way an activity is performed. However, there is no information on which activities have been amended in this way or by how much. Such a 'hidden' correction makes it difficult to assess the general relevance of the values provided but a calculation of the consequences of the energy costs used in the reports is instructive. The mid-point of the range for average jogging in the Department of Health (1991) report is BMR $\times 7 \cdot 0$, yet if we use the data of Margaria et al. (1963) to calculate the speed which would correspond to this level of expenditure for an untrained individual the result is $6.6 \mathrm{~km} / \mathrm{h}(4 \mathrm{miles} / \mathrm{h})$. This is not jogging but walking. Thus, although the values presented by Margaria et al. (1963) are not valid for walking, this type of calculation serves to illustrate that the energy 
cost of jogging presented in the Department of Health (1991) report may be so low as to be inconsistent with the performance of this activity. It is possible that some individuals may not be able to do much more than walk but the values of BMR $\times 6$ to 8 suggested by Department of Health (1991) appear to have been used in the calculation of energy expenditure in all individuals, regardless of their habitual level of leisure activity. Therefore an inherent assumption would appear to be that there is little or no training effect resulting from regular performance of an activity, either on aerobic capacity or on the number of 'rest periods' required, and that the difference between 'non-active' and 'very-active' leisure lies only in the time spent in a relatively low intensity of exercise.

This discussion has concentrated on one type of exercise (jogging or running) since this was chosen to be the main leisure pursuit of the active individuals studied. However, the same argument may be used to explain the apparent discrepancy between the Department of Health (1991) reference values for energy and the DLW-derived TEE of individuals with other active leisure pursuits since the range of energy costs for other activities in the report is also narrow and no value above $\mathrm{BMR} \times 8$ appears to have been used to calculate the reference values.

Although too many adults in the UK are inactive, a quarter of all adult males do engage in regular vigorous or moderate exercise (Allied Dunbar National Fitness Survey, 1992). We have argued, on the basis of direct measurements, that the energy requirements of such a significant proportion of the population do not appear to be adequately covered by the most recent Department of Health (1991) guidelines. However, this assertion is based on measurements in only a small number of subjects. It is therefore important to obtain more detailed survey information (using field methodologies such as heart rate monitoring) on the way in which leisure activity is currently performed in the UK population. A more realistic estimate of the potential impact of regular exercise on energy balance might encourage more of the population to take up active leisure pursuits.

The authors would like to thank Dr R. Maughan for helpful discussions on the energy cost of running. This work was funded by The Scottish Office Agriculture and Fisheries Department.

\section{REFERENCES}

Allied Dunbar National Fitness Survey (1992). A Report on Activity Patterns and Fitness Levels. London: Health Education Authority and Sports Council.

Bahr, R. (1992). Excess post exercise oxygen consumption - magnitude, mechanisms and practical implications. Acta Physiologica Scandinavica 144 Suppl. 605, 1-70.

Black, A. E., Prentice, A. M. \& Coward, W. A. (1986). Use of food quotients to predict respiratory quotients for the doubly labelled water method of measuring energy expenditure. Human Nutrition: Clinical Nutrition 40C, 381-391.

Davidson, L., McNeill, G., Haggarty, P. \& Smith, J. S. (1993). Measurement of free-living energy expenditure by continuous heart rate monitoring and doubly-labelled water. Proceedings of the Nutrition Society 52, 93A.

Department of Health (1991). Dietary Reference Values for Food Energy and Nutrients for the United Kingdom. Report on Health and Social Subjects no. 41. London: H.M. Stationery Office.

Department of Health and Social Security (1979). Recommended Daily Amounts of Food Energy and Nutrients for Groups of People in the United Kingdom. Report on Health and Social Subjects no. 15. London: H.M. Stationery Office.

Durnin, J. V. G. A. (1984). Some problems in assessing the role of physical activity in the maintenance of energy balance. In Energy Intake and Activity. Current Topics in Nutrition and Disease, vol. 11, pp. 101-113. [E. Politt and P. Amante, editors]. New York: Alan R. Liss Inc.

Durnin, J. V. G. A. (1985). The energy cost of exercise. Proceedings of the Nutrition Society 44, $273-282$.

Edholm, O. G., Fletcher, J. G., Widdowson, E. M. \& McCance, R. A. (1955). The energy expenditure and food intake of individual men. British Journal of Nutrition 9, 286-300.

Food and Agriculture Organization/World Health Organization/United Nations University (1985). Energy and Protein Requirements. Report of a Joint Expert Consultation. WHO Technical Report Series, no. 724. Geneva: WHO. 
Haggarty, P. (1990). The effect of isotope sequestration and exchange. In IDECG Report. The Doubly Labelled Water Method for Measuring Energy Expenditure. Technical Recommendations for Use in Humans, pp. 114-146 [A. M. Prentice, editor]. Vienna: International Atomic Energy Agency.

Haggarty, P., Franklin, M. F., Fuller, M. F., McGaw, B. A., Milne, E., Duncan, G., Christie, S. L. \& Smith, J. S. (1994). Validation of the doubly labeled water method in growing pigs. American Journal of Physiology (In the Press).

Haggarty, P., Franklin, M. F. \& McGaw, B. A. (1988a), Advantages and limitations of the double labelled technique to measure energy expenditure. In Obesity in Europe 1, pp. 365-370 [P. Bjorntrop and S. Rossner, editors].

Haggarty, P., McGaw, B. A. \& Franklin, M. F. (1988b). Measurement of fractionated water loss and $\mathrm{CO}_{2}$ production using triply labelled water. Journal of Theoretical Biology 134, 291-308.

Humphrey, S. J. E. \& Wolf, H. S. (1977). The Oxylog. Journal of Physiology 12P, 267.

James, W. P. T. \& Schofield, E. C. (1990). Human Energy Requirements. Oxford: Oxford University Press.

Kuno, Y. (1956). Human Perspiration. Springfield, IL: Charles C. Thomas.

Lifson, N. \& McClintock, R. (1966). Theory of use of the turnover rates of body water for measuring energy and material balance. Journal of Theoretical Biology 12, 46-74.

Livingstone, M. B. E., Prentice, A. M., Strain, J. J., Coward, W. A., Black, A. E., Barker, M. E., McKenna, P. G. \& Whitehead, R. G. (1990). Accuracy of weighed dietary records in studies of diet and health. British Medical Journal 300, 708-712.

Livingstone, M. B. E., Strain, J. J., Prentice, A. M., Coward, W. A., Nevin, G. B., Barker, M. E., Hickey, R. J., McKenna, P. G. \& Whitehead, R. G. (1991). Potential contribution of leisure activity to the energy expenditure patterns of sedentary populations. British Journal of Nutrition 65, 145-155.

Maehlum, S., Grandmontagne, M., Newsholme, E. A. \& Sejersted, O. M. (1986). Magnitude and duration of excess postexercise oxygen consumption in healthy young subjects. Metabolism 35, 425-429.

Margaria, R., Cerretelli, P., Aghemo, P. \& Sassi, G. (1963). Energy cost of running. Journal of Applied Physiology 18, 367-370.

McNeill, G., Bruce, A., Ralph, A. \& James, W. P. T. (1988a). Inter-individual differences in fasting nutrient oxidation and the influence of diet composition. International Journal of Obesity 12, 455-463.

McNeill, G., McBride, A., Smith, J. S. \& James, W. P. T. (1989). Energy expenditure in large and small eaters. Nutrition Research 9, 363-372.

McNeill, G., Payne, P. R. \& Rivers, J. P. W. (1988b). Socio-economic and seasonal patterns of adult energy nutrition in a S. Indian village. Ecology of Food and Nutrition 22, 85-95.

Midwood, A. J., Haggarty, P. \& Milne, E. (1992). Analysis of ${ }^{18} \mathrm{O}$-enriched aqueous samples using $\mathrm{CO}_{2}$ equilibration in Vacutainers. Applied Radiation and Isotopes 43, 1341-1347.

Passmore, R. \& Durnin, J. V. G. A. (1967). Energy, Work and Leisure. London: Heinemann Educational Books Ltd.

Roberts, S. B., Heyman, M. B., Evans, W. J., Fuss, P., Tsay, R. \& Young, V. R. (1991). Dietary energy requirements of young adult men, determined by using the doubly labeled water method. American Journal of Clinical Nutrition 54, 499-505.

Schocller, D. A. \& Coward, A. W. (1990). Isotope fractionation corrections. In IDECG Report. The Doubly Labelled Water Method for Measuring Energy Expenditure. Technical Recommendations for Use in Humans, pp. 90-113 [A. M. Prentice, editor]. Vienna: International Atomic Energy Agency.

Schoeller, D. A., Ravussin, E., Schutz, Y., Acheson, K. J., Baertschi, P. \& Jequier, E. (1986). Energy expenditure by doubly labeled water: validation in humans and proposed calculation. American Journal of Physiology 250, R823-R830.

Weir, J. B. De V. (1949). New methods of calculating metabolic rate, with special reference to protein metabolism. Journal of Physiology 109, 1-9.

Westerterp, K. R., Meijer, G. A. L., Jansen, E. M. E., Saris, W. H. M. \& Ten Hoor, F. (1972). Long-term effect of physical activity on energy balance and body composition. British Journal of Nutrition 68, 21-30.

Wong, W. W., Lee, L. S. \& Klein, P. D. (1987). Deuterium and oxygen-18 measurements in microlitre samples of urine, plasma, saliva and human milk. American Journal of Clinical Nutrition 45, 905-913. 